CATALAN REVIEW

Catalan Review

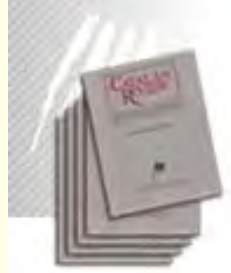

You are accessing the Digital Archive of the Catalan Review Journal.

By accessing and/or using this Digital Archive, you accept and agree to abide by the Terms and Conditions of Use available at http://www.nacs-

catalanstudies.org/catalan_review.html

Catalan Review is the premier international scholarly journal devoted to all aspects of Catalan culture. By Catalan culture is understood all manifestations of intellectual and artistic life produced in the Catalan language or in the geographical areas where Catalan is spoken. Catalan Review has been in publication since 1986 .
NORTH

AMERICAN

CATALAN

SOCIETY
Esteu accedint a l'Arxiu Digital del Catalan Review

A l' accedir i / o utilitzar aquest Arxiu Digital, vostè accepta i es compromet a complir els termes i condicions d'ús disponibles a http://www.nacs-

catalanstudies.org/catalan_review.html

Catalan Review és la primera revista internacional dedicada a tots els aspectes de la cultura catalana. Per la cultura catalana s'entén totes les manifestacions de la vida intel lectual i artística produïda en llengua catalana o en les zones geogràfiques on es parla català. Catalan Review es publica des de 1986.

\title{
Innovació i tradició en la poesia catalana del segle XVI August Bover i Font
}

Catalan Review, Vol. II, number 1 (1987), p. 41-68 


\title{
INNOVACIÓ I TRADICIÓ \\ EN LA POESIA CATALANA DEL SEGLE XVI
}

\author{
AUGUST BOVER I FONT
}

Qualsevol estudi sobre la poesia catalana del segle XVI topa avui, forçosament, amb tota una sèrie de dificultats: manca d'edicions o edicions poc fiables, obres perdudes, gran quantitat de manuscrits $i$ de plecs solts encara no catalogats - i, per tant, desconeguts,$-{ }^{1}$ etc., sense oblidar l'extraordinària acidesa de la tinta emprada per aquestes latituds en aquells temps, cosa que, en el millor dels casos, dificulta en gran manera la lectura de molts manuscrits. I tot plegat emmarcat pels greus problemes de periodització, encara pendents de resolució, que presenta aquest segle. Tenint en compte tot això, es fa evident que qualsevol estudi de conjunt només podrà arribar, ara per ara, a unes conclusions provisionals. ${ }^{2} \mathrm{~A}$ desgrat d'aquestes dificultats, però, intentaré de traçar les principals línies de força que es dibuixen en aquest període de la nostra poesia.

Allò que primer crida l'atenció quan hom contempla el panorama poètic català de l'època del Renaixement és la gran di-

${ }^{1}$ Actualment estic preparant un "Repertori de manuscrits i edicions de poesia catalana del segle Xv"".

${ }^{2}$ La situació és semblant a tota la Península. Pel que fa a Castella - per exemple -: "La poesía de cronología renacentista (...) es, en muchos casos, una duda textual, a veces una confusión, y siempre la sospecha, o la esperanza, de que el tiempo nos irá deyolviendo textos que hoy desconocemos y que quizás puedan sorprendernos. En gran parte, esta situación constituye una característica de la poesía de este período (...)", diu Antonio Prieto, La poesía española del siglo XVI. I. Andáis tras mis escritos (Madrid 1984), 19; veg. també Antonio Rodríguez-Moñino, Construcción crítica y realidad bistórica en la presía de los siglos XVI y XVII, Madrid, $1968^{2}$. 
versitat de camins que s'hi troba, de manera que la persistència de la poesia trobadoresca, la gran influència ausiasmarquiana, les novetats italianitzants, l'acostament dels poetes cultes a la lírica de cançoner, etc., fan que la nostra poesia, com la d'arreu de la Romània, sigui un autèntic melting-pot. I, curiosament, de tota aquesta "colla de ruptures $\mathrm{i}$ de desigualtats, de substitucions i de buits" que constituïa el pensament literari del país, per dirho amb mots de Joaquim Molas, ${ }^{3}$ no ens n'ha arribat cap tractat de preceptiva que mirés de posar-hi ordre o, si més no, se'n fes ressò. ${ }^{4}$

Efectivament, com a tot Europa, ${ }^{5}$ els humanistes catalans, de Joan Lluís Vives a Frederic Furió i Ceriol, estudiaven els models de l'antiguitat clàssica $i$, en general, defugien la literatura en llengua vulgar, i el fet que unes notes de Pere Joan Nunyes sobre la poètica d'Aristòtil siguin parcialment en català no canvia les coses. ${ }^{6}$ No és estrany, doncs, que els seus treballs no exercissin "cap influència apreciable en la literatura militant: la moderna"?

Però del costat de la literatura en llengua vulgar tampoc no ens n'ha arribat gran cosa. El 1538, el poeta mallorquí Francesc d'Olesa publicà una art de trobar amb unes certes pretensions de renovació: "En tant que no pens se farà injúria a algú si

3 "Francesc Calça: Poemes", Els Marges, 14 (1978), 77.

${ }^{4}$ Veg. Albert Rossich, Una poètica del Barroc. El "Parnàs Catalä" (Girona 1979), 19-20 i $24-25$.

${ }^{5}$ Veg, l'estudi de Paul Oskar Kristeller "Els antecedents medievals de l'humanisme renaixentista", dins Eight Philosophers of the Italian Renaissance (Stanford 1964). [Per raons pràctiques empro la trad. esp.: Ocho filósofos del Renatimiento italiano (Mèxic 1970), 191-212.] Veg. també Antonio Vilanova, "Preceptistas españoles de los siglos xvI y XVI", dins Guillermo Diaz-Plaja [dir.], HGLH, III (Barcelona 1968²), 567-570.

${ }^{6}$ Veg. A. Rossich, Una poètica..., "20, nota 2.

7 J. Molas, Francesc Calca..., 77. 
s'anomena art nova", ${ }^{8}$ Ara bé, aquesta voluntat de l'autor no va més enllà de citar la Gramàtica d'Antonio de Nebrija o d'esmentar un parell de versos d'Ausiàs March. Com diu Martí de Riquer, "Aquest Art de trobar, malgrat les afirmacions de novetat contingudes al prefaci (...), exposa una doctrina $\mathrm{i}$ unes regles que ja coneixien els catalans de principis del segle XII". 9

Tota una altra cosa devia ser 1"'Arte poética en romance castellano" que sembla que Pere Serafí tenia ja enllestida a començaments de 1564. Si més no, en un document del 27 de març de 1564, Felip I (II de Castella) atorgava al pintor-poeta el permís per a l'estampació de la seva art poètica i dels seus dos llibres de poesia "de sonetos y otras rimas, en diversos subjetos, el uno en romance castellano y el otro en lengua catalana". ${ }^{10}$ I més endavant, el 16 de juny de 1565 , Serafí signà un contracte davant notari amb el donzell Jeroni Galceran Serapi de Sorribes i el mercader Francesc Creus, per tal d'imprimir les obres esmentades. ${ }^{11}$ Aquesta art poètica, però, igual que la "Silva de diverses obres de poesia" en castellà, sembla perduda, ${ }^{12} \mathrm{i}$, com ha observat Josep Romeu i Figueras, ${ }^{13}$ molt probablement no es devia

${ }^{8}$ Francesc d'Olesa, Art Nova de Trobar, edició a cura de Jaume Vidal i Alcover (Montserrat 1986), 83.

${ }^{9}$ HLC, III, Esplugues de Llobregat, 1964, 381.

${ }^{10}$ Veg. Josep M. Madurell, "Algunas antiguas ediciones barcelonesas de libros (1502-1704)”, BRABLB, XXIV (1951-1952), 161-162.

"I Veg. Josep M. Madurell, "Pedro Nunyes y Enrique Fernandes, pintores de retablos", Anales y Boletín de los Museos de Arte de Barcelona, II-3 (1944), 16, n. 10.

12 "No es va arribar a imprimir? ¿O han desaparegut els seus exemplars? No és inversemblant, si tenim en compte com són extremament rars els de l'edició de les poesies [catalanes]", insinua Jordi Rubió i Balaguer, HLC, II, Montserrat, 1985, 38.

13 "Poemes en castellà atribuïbles a Pere Serafi", BRABLB, XXXVI (19751976), 138-139. 
arribar a imprimir si tenim present que, el 1566, Serafí tenia serioses dificultats econòmiques i que segurament patia una greu malaltia, de la qual devia morir els primers dies del 1567 . La pèrdua d'aquesta art poètica és ben de doldre perquè Serafi era "un bon coneixedor de la preceptiva trobadoresca i catalana medieval, la castellana, la italiana i la francesa i que no menyspreava els gèneres pópulars", ${ }^{14}$ i perquè el seu treball és força anterior a la primera preceptiva renaixentista que hom coneix a la Península, em refereixo a El arte poética en romance castellano, del portuguès Miguel Sánchez de Lima, publicada a Alcalá de Henares el $15800^{15}$

Així, doncs, l'aparició de la nova poesia italianitzant catalana tampoc no va anar acompanyada d'una preceptiva que la codifiqués. Això no obstant, humanistes i poetes feren conèixer les seves formulacions teòriques a través d'altres camins. ${ }^{16}$ Per exemple, les edicions i comentaris humanístics dels clàssics, que en alguns casos s'estengueren a autors en vulgar; els textos valoratius dels certàmens poètics (cartells de convocatòria, sentències i vexàmens) ${ }_{3}^{17}$ els comentaris continguts en les aprovacions, les dedicatòries o els poemes laudatoris que encapçalaven moltes obres; el gènere epistolar $\mathrm{o}$, fins i tot, la mateixa obra literària. I en una època en què la clàssica doctrina de la imitació - reelaborada per Sèneca, convalidada per Dante i Petrarca, sancionada per Pietro Bembo a les Prose della volgar lingua (1525) i recollida per Joachim Du Bellay a la Défense et illustration de la

${ }^{14} \mathrm{M}$. de Riquer, $H L C$, III, 613.

${ }^{15}$ Veg. ibid., 613 i 615, i en especial per a l'obra de Sánchez de Lima: A. Vilanova, "Preceptistas...", HGLH, III, 585-586 i 589-594.

${ }^{16}$ Veg. J. Molas, "Francesc Calça...”, 78.

${ }^{17} \mathrm{Val}$ a dir, però, que en aquesta època els certàmens no són excessivament freqüents. Veg. J. Rubió, HLC, II, 25-30 i Antoni Ferrando Francés, Els certàmens poittics valencians del segle XIV al XIX, València, 1983, 877. 
langue française (1549) - havia esdevingut el centre de la nova poètica, ${ }^{18}$ de cap manera no es pot oblidar l'estímul que, per a la poesia culta en llengua vulgar, havia de significar l'exercici humanístic de les traduccions i la pràctica, encara que només fos pedagògica, de la poesia llatina, ${ }^{19}$ però que comptava amb conreadors ben significatius, com per exemple un Petrarca no gens negligible $i$, de feia temps, ben conegut als Països Catalans, ${ }^{20}$ el mateix Andrea Navagero que l'estiu de 1526, a Granada, li deia a Boscà "por qué no provava en lengua castellana sonetos y otras artes de trobas usadas por los buenos authores de Italia"; o bé, dintre del nostre àmbit, autors com Antoni Brenach, Francesc Calça o Martí Ivarra. Sense l'orientació de les regles de la preceptiva, la renovació renaixentista de la poesia catalana per força havia de produir-se a través de la imitació d'uns

${ }^{18}$ En el prefaci de la seva versió llatina de les cartes de Plató, adreçada a Cosimo de Mèdici, Leonardo Bruni, l'Areti, deia significativament: "Fateor in his magnum et absolutum quendam virum bonum nihi ad imitandum proponi; imitationes vero nonnunquam efficaciores sunt quam doctrine..."; veg. el que en diuen Eugenio Garin en el seu estudi "La prosa llatina del segle XV", dins Medioevo e Rinascimento. Studi e ricerche, Roma-Bari, 1973 [Ed. esp.: Medioevo y Renacimiento. Estudios e investigaciones, Madrid, 1981, 93-94]; R.O. Jones, The Golden Age: Prose and Poetry. The Sixteenth and Seventeenth Centtiries, Londres, 1971 [Ed. esp.: Historia de la literatura española, 2. Siglo de Oro: prosa y poesía (Siglos XVI y XVII), Sant Joan Despí, 1981', 147]; i Fernando Lázaro Carreter, "Imitación compuesta y diseño retórico en la oda a Juan Grial", Anuario de estudios filológicos, II (1979), 94-101 i 117-119, passatges recollits amb el titol de "Imitación y originalidad en la poética renacentista” dins Francisco Rico [dir.] Historia y crítica de la literatura española. 2. Siglos de oro: Renacimiento, a cura de Francisco López Estrada, Barcelona, 1980, 91-97.

19 Veg. A. Prieto, La poesía..., 184-191.

20 "Petrarca morí, en plena glòria, el 1374; uns deu anys després les seves obres escrites en llati ja eren divulgades per Catalunya, traduïdes, admirades i imitades per Bernat Metge, conegudes de tothom i fins i tot citades en lletres i en discursos parlamentaris", recorda M. de Riquer, HLC, I, Barcelona, 1964, 611-612. 
determinats models, tal com s'esdevé, per exemple, a Castella, que en aquest sentit es trobava en las mateixes circumstàncies.

Però, com ja he insinuat abans, la innovació només és una de les característiques de la poesia de l'època renaixentista. De fet, i potser més que cap altra època històrica, el Renaixement engloba elements vells $i$ nous, tot formant una barreja que ha arribat a confondre més d'un historiador. ${ }^{21}$ No podem parlar, doncs, d'una línia divisòria entre l'Edat Mitjana i el Renaixement sinó més aviat d'una gradació; és per això que una definició de Renaixement sempre resultarà incompleta. En canvi, com veurem, serà molt més efectiu mirar de resseguir els elements tradicionals i els innovadors i permetre, d'aquesta manera, ${ }^{22}$ que el Renaixement s'autodefineixi com la suma dels canvis operats, sobretot si tractem - com és el cas - de la península Ibèrica, on la convivència dels dos tipus d'elements hi tingué un arrelament especial.

$$
* * *
$$

Com és ben sabut, no es pot parlar pròpiament de Renaixement en la poesia europea fins al "descobriment" del Petrarca del Canzoniere i dels seus seguidors. En els regnes hispànics, aquesta internacionalització de la literatura italiana va ser facilitada per l'increment que en el segle XVI experimentà l'activitat diplomàtica, de gran importància per a la transmissió de les idees. Pel que sembla tot va començar amb la conversa - al-ludida anteriorment - que el barceloní Joan Boscà i l'ambaixador venecià

21 Veg. E. Garin, "Interpretacions del Renaixement", Medioevo y Renacimiento..., 69-81, i "Edats obscures i Renaixement: un problema de límits", dins $R i$ nascite e rivoluzioni. Movimenti culturali dal XIV al XVIII secolo, Bari, 1976, 3-38. [Trad. esp. dins de La revolución cultural del Renacimiento, Barcelona, 19842, 29-71].

22. Veg. l'opinió de R.O. Jones, Historia..., 24. 
Andrea Navagero van mantenir, en un passeig estival pels jardins del Generalife de Granada, l'any 1526, tal com Boscà ho explica en la seva carta $A$ la duquesa de Soma. ${ }^{23}$ A començaments de segle, però, l'ambient poètic era ben diferent. La impremta contribuí en gran manera a la consolidació de gèneres com és ara la cançó, el romanç, etc., a través dels cançoners i dels plecs solts. L'anomenada lírica de cançoner, ben arrelada ja en el segle XV a tota la Península, donà origen a algunes "antologies" d'extraordinària difusió durant el XVI, la més important de les quals, el Cancionero general d'Hernando del Castillo, es publicà per primer cop a València el 1511 i s'hi reedità el 1514, amb la inclusió de catorze poemes en català, abans d'iniciar el seu gran èxit editorial hispano-flamenc. ${ }^{24}$ L'èxit d'aquest cançoner n'estimulà d'altres, molts dels quals es van editar i reeditar a València i a Barcelona, en alguns casos amb una petita presència de composicions en llengua catalana llevat del Cancionero llamado Flor de enamorados, que és el que hi dedica més espai. ${ }^{25}$ I com als regnes d'Aragó i de Castella, a Portugal hi trobem també la mateixa situació amb la publicació del Cancioneiro Geral de García de Resende (Lisboa 1516). ${ }^{26}$

D'altra banda, tot i la il-lusió humanística de ressuscitar el llatí com a llengua viva de la literatura, la tan renaixentista "questione della lingua" s'anà decantant arreu a favor de les llengües

${ }^{23}$ Obras poéticas de Juan Boscán, I (Ed. crítica de M. de Riquer, A. Comas i J. Molas), Barcelona, 1957, 87-91.

${ }^{24}$ Veg. Antonio Rodríguez-Moñino, "La Flor de los enamorados, cancionero bilingüe. Ensayo bibliográfico (1562-1954)", Estudis Romànics, XI (1962), 33-47.

${ }^{25}$ Veg. Josep Romeu i Figueras, Joan Timoneda $i$ la "Flor de enamorados", canconer bilingüe. Un estudi i una aportació bibliográfica, discurs d'ingrés a la RABLB, 20/II/1972, Barcelona, 1972, i la "Introducció" de Joan Fuster a Joan Timoneda, Flor d'enamorats, València, 1973, 7-43.

${ }^{26}$ Veg. José Filgueira Valverde, "Lírica medieval gallega y portuguesa", HGLH, I, Barcelona, 1969², 621-622. 
vulgars. Sobretot des del moment en què Bembo, a les Prose..., sense posar en dubte la superioritat de la llengua llatina, defensa la creació d'una llengua poètica que hi pugui competir en expressivitat $\mathrm{i}$ eficàcia $\mathrm{i}$ beneeix l'opció que un humanista tan prestigiós com Petrarca havia adoptat en el Canzoniere. Es tracta de la mateixa posició que prendrà Du Bellay en la Défense... Però la "questione" entre llatí o vulgar tenia una segona part: quin vulgar? A Itàlia, Bembo rebutjà la llengua cortesana i, tot fent una síntesi dels altres dos criteris predominants - és a dir, el que defensava el toscà parlat per persones de cultura i el que defensava la llengua dels bons escriptors -, s'inclinà per la llengua dels bons escriptors toscans del "Trecento" (Petrarca i Boccaccio, bàsicament). A casa nostra, en canvi, les coses van anar d'una altra manera. D'entrada l'estructura política era diferent: mentre que a allò que, per entendre'ns, en diem Itàlia el poder estava molt més repartit i hi havia una sèrie de corts d'importància més o menys similar, a la Corona d'Aragó hi havia, per damunt de totes, la cort del monarca. I el monarca, des de la mort de Martí l'Humà sense successió (1410), ja no era de nis-. saga catalana; amb el compromís de Casp (1412) s'havia entronitzat la dinastia castellana dels Trastàmara. El procés de castellanització s'havia posat en marxa, i el casament dels Reis Catòlics, que conduirà a la unió dinàstica amb Castella, clarament desfavorable per a la Confederació catalano-aragonesa, no farà altra cosa que empitjorar la situació. ${ }^{27}$ Aquesta situació, en una època com la del Renaixement, on l'activitat cultural era emi-

${ }^{27}$ Veg. Antoni Comas, "Problemàtica de la Decadencia", recollit últimament dins Estudis de literatura catalana (segles XVI-XVIII), a cura d'A. Bover i M. de Ciurana, Barcelona, 1985, 30-39. Evidentment, aquest només és un dels molts factors que intervenen en aquest procés, però - com ha recordat recentment Joan Fuster - no es pot pas considerar com un element de segon ordre: "Decadència i castellanització", Caplletra, 1 (1986), 29-30. 
nentment àulica, havia de tenir unes conseqüències fatals, encara que es veiés fins a cert punt contrarestada, per exemple, pel mecenatge cultural dels Cardona. ${ }^{28}$ Ara, la pregunta: quin vulgar? volia dir: català o castellà? ${ }^{29} \mathrm{I}$ és ben clar quina era la resposta més avantatjosa. El mateix procés el trobem a Portugal en extingir-se la dinastia d'Aviz i ser reconegut com a rei Felip II de Castella (1580). La cort portuguesa desapareix i molts escriptors se'n van a la de Madrid - si bé a l'interior continua l'activitat cultural dels ducs de Bragança, dels comtes de Vila Real o dels convents d'Alcobaça i de Santo Domingo de Bemfica -, i tant entre els que se'n van com entre els que es queden el conreu literari del castellà s'intensifica de manera alarmant. ${ }^{30}$ Aquest és, breument, l'statu quo poètic i lingüístic que trobarà la generació de Joan Boscà.

És, doncs, en aquest marc que es produirà la revolució poètica iniciada, per Boscà i per Garcilaso mercès, com a tot arreu, als contactes directes o indirectes amb Itàlia. El punt de partida, la conversa entre Boscà i l'ambaixador Navagero, es veurà potenciat per les missions polítiques. Tal és el cas de Garcilaso,

${ }^{28}$ Veg. J. Rubió, Els Cardona i les lletres, discurs d'ingrés a la RABLB, 7/IV/1957, Barcelona, 1957.

${ }^{29}$ Veg. Max Cahner, "Llengua i societat en el pas del segle XV al XVI", Actes del Cinquè Col-loqui Internacional de Llengua i Literatura Catalanes, Andorra, 1-6 d'octubre de 1979, a cura de J. Bruguera i J. Massot, Montserrat, 1980, 183-255; i també el treball de Philippe Berger, "Contribution à l'étude du déclin du valencien comme langue littéraire au seizième siècle", Melanges de la Casa de Velázquez, XII (1976), 173-194. D’altra banda, sembla que la població jueva ja havia pràcticament abandonat l'ús de l'hebreu, la minoria islàmica sí que mantenia la seva llengua, però constituĩa un món tancat i marginat; i el conreu literari de l'italià per part dels escriptors catalans sempre va ser ocasional $\mathrm{i}$ anecdòtic: veg. J. Fuster, "Decadència i...", 30.

${ }^{30} \mathrm{Veg}$. António José Saraiva, Breve bistoria de la literatura portuguesa, Madrid, 1971, 120-121. 
amb les seves estades a Nàpols, o el de Francisco de Aldana, segons que sembla nascut a Nàpols, i format a Florència. ${ }^{31}$ De la mateixa manera que l'exili de Clément Marot a Ferrara (1535) representarà una renovació $\mathrm{i}$ un enriquiment per a la poesia francesa, continuats pel cercle de Margarida de Navarra i, sobretot, pel grup de Lió, a mig camí d'Itàlia, a l'entorn de Louise Labé i liderat per Maurice Scève, que prepararan i acceleraran el triomf renaixentista que suposa la Pléiade, proclamat amb entusiasme a la Défense..., de Du Bellay, tot i que el grup experimentarà una reacció antipetrarquista cap al $1553 .{ }^{32} \mathrm{La}$ mateixa renovació i el mateix enriquiment que, per a Portugal, comportaran els sojorns italians de Bernadim Ribeiro i de Francisco de Sá de Miranda, el qual el 1526, de tornada cap a Portugal, es reuní amb Boscà i Garcilaso. ${ }^{33}$ En canvi, i malgrat les estretes relacions ítalo-catalanes, no fou aquest el canal per on arribà la renovació a la poesia catalana. L'obra de Joan Boscà, totalment en castellà, ${ }^{34}$ s'inscriu, lògicament, en la literatura espanyola. ${ }^{35}$ Les relacions comercials i militars de la Corona d'Aragó amb Itàlia, tan importants a l'època d'Alfons el Magnànim i de Calixt III $i$, de nou, a la de Ferran el Catòlic i d'Alexandre VI, sobretot pel que fa a

${ }^{31}$ Veg., per exemple, R.O. Jones, Historia..., 67-68 i 154-155, respectivament. ${ }^{32}$ Veg., per exemple, Pierre Brunel i altres, Histoire de la littérature française, I, Nancy, $1977^{2}$, 94-99 i 111-128.

${ }^{33} \mathrm{Veg}$. A. J. Saraiva i Óscar Lopes, História da literatura partuguesa, Porto, $1976^{9}, 259-260$.

${ }^{34}$ Només li coneixem una sola composició en llengua catalana, una esparsa clarament ausiasmarquiana. Veg. M. de Riquer, Juan Boscán y su cancionero barcelonés, Barcelona, 1945, 57-60. Quan era a punt de lliurar aquest article i gràcies a l'amistat d'Albert Rossich, he pogut consultar el seu article "La introducció de la mètrica italiana en la poesia catalana", de publicació imminent a la revista Els Marges, 35; veg. la seva opinió sobre l'esparsa catalana de Boscà.

${ }^{35}$ Veg. la monografia que Marcelino Menéndez Pelayo dedicà a aquest poeta: Antología de poetas líricos castellanos, X, Santander, 1945. 
l'eix València-Nàpols, haurien hagut de tenir unes conseqüències literàries importants. Però - com diu Joan Fuster - "sembla que no fou així, o que només ho fou a mitges". ${ }^{36} \mathrm{I}$, de tots els poetes catalans que en aquestes èpoques es relacionaren amb Itàlia, l'únic autor que aprofità la seva estada a Nàpols en aquest sentit, el barceloní Benet Garret, que s'hi traslladà el 1467, mai no va tornar als Països Catalans. La seva italianització fou total, fins i tot lingüística: ingressà a l'Accademia Pontaniana amb el pseudònim de Il Chariteo i publicà el seu cançoner Endimione (Nàpols 1506; ampliat el 1509) on la nostàlgia de la seva Barcelona natal ("Pianga Barcino, antiqua patria mia...") es fa present en algunes composicions. ${ }^{37} \mathrm{D}$ 'altra banda, no ha estat gaire estudiada la influència que les colònies de mercaders italians establertes a casa nostra van poder tenir com a introductors d'elements renovadors, però no sembla que hi tinguessin un paper gaire rellevant. De la colònia que residia a València - recorda Fuster -, "almenys hi ha constància d'un poeta italià, Bartolomeo Gentile, participant en el Cancionero General amb uns sonets religiosos en la seva llengua". I "tampoc no "petrarquit$\mathrm{za}^{\prime \prime},{ }^{38}$

Per tant, sense uns contactes fructífers tant se val si a l'interior o a l'exterior, la renovació poètica catalana només es podia produir a través de la lectura i de la imitació. Alguns poetes van mostrar-se pràcticament impermeables a les innovacions, són els que es manifestaven a través dels certàmens poètics. "No diré que els poetes que acudien a aquells certàmens fossin uns retar-

36 "Lectures d'Ausiàs Marc en la València del segle Xv1", dins Universitat de Barcelona. Solemne investidura de doctor bonoris causa a Joan Fuster..., Barcelona, 1984, 19.

${ }^{37}$ Veg. Le Rime del Chariteo, introducció i notes a cura d'Erasmo Pèrcopo, Nàpols, 1892, i Marcelino Menéndez y Pelayo, Antologia..., X, 384-397.

${ }^{38} \mathrm{~J}$. Fuster, Lectures..., 23-24. 
dataris, però des del moment que se sotmetien a llurs convencionalismes, l'acceptació d'aquests sembla agermanar-los amb certs trets comuns i anacrònics", diu Jordi Rubió. ${ }^{39}$ Però, lògicament, d'altres van ser totalment receptius envers les novetats. I evidentment, sobretot a Barcelona, Joan Boscà no podia passar pas desapercebut. Un poeta que, amb una claríssima visió de futur, s'arrenglera de manera inequívoca com pocs altres amb la modernitat, necessàriament havia de fer sentir la seva influència. Boscà explicava a la duquessa de Somma: "De manera que este género de trobas, y con la authoridad de su valor proprio y con la reputación de los antiguos y modernos que le han usado, es dino, no solamente de ser recebido de una lengua tan buena, como es la castellana, mas aún de ser en ella preferido a todos los versos vulgares. $\mathrm{Y}$ assí pienso yo que lleva camino para sello" ${ }^{40}$ D'acord amb aquesta visió, renuncià a les cobles castellanes i, amb el seu amic Garcilaso, representarà l'opció més radical a favor dels models italians. I de tots aquests models possibles, el poeta barceloní sembla seguir les preferències poètiques de Pietro Bembo: ${ }^{41}$ la lectura del Canzoniere de Petrarca com a biografia, com a autèntica història d'amor, $i$ la seva teoria sobre l'amor platònic, exposada a la fi de Il Cortegiano de Baldassarre Castiglione, llibre excel-lentment traduit al castellà pel propi Boscà a proposta de Garcilaso. Bembo, doncs, farà que petrarquisme i platonisme vagin sovint units, i aquesta conjunció la retrobem en Boscà. D'aquí, per exemple, que incorpori la dona al món cultural, com es pot veure en la dedicatòria "A la Muy Magnífica Señora Doña Gerónima Palova de Almogávar" de El

${ }^{39}$ HLC, II, 25. Veg. també A. Ferrando, Els certàmens..., 141.

${ }^{40} \mathrm{M}$. de Riquer, Obras poéticas..., 91.

${ }^{41}$ Veg. Carlo Salinari, Profilo storico della letteratura italiana, II, Roma, 1972², 15-19, i A. Prieto, La poesía..., 60-61. 
Cortesano (Barcelona 1534) o en la carta a la duquessa de Somma del llibre segon de les seves obres poètiques (Barcelona 1543), que recorden l'epístola llatina de Miquel Jeroni Cruilles adreçada a Jerònima Exarche continguda en la segona edició de l'Spill de la vida religiosa (València 1529). ${ }^{42}$ D'altra banda, també cal tenir present que Boscà trobarà en la tradició peninsular part del que li arriba d'Itàlia, fenomen perfectament explicable pel comú origen provençal. És el cas d'Ausiàs March, tan pròxim a Petrarca en més d'un aspecte, ${ }^{43}$ l'admiració pel qual va saber transmetre a Garcilaso i companyia, fins al punt que es creà un clima d'interès general que arribà a produir diverses traduccions $i$ les edicions catalanes sota els auspicis del segon duc de Somma i almirall de Nàpols, Ferran Folch de Cardona ${ }^{44}$ De fet, formalment, la gran novetat de Boscà és l'ús del decasíllab (endecasilabo) italià, vers que d'alguna manera li havia de ser familiar mercès a March i a la tradició lírica catalana. I al costat d'aquest vers, les innovacions italianitzants de Boscà i Garcilaso significaren la definitiva incorporació del sonet i la introducció de l'octava, inventada per Boccaccio en la Teseida; i, encara que en el Canzoniere no n'hi havia, de la sàtira, l'epístola, l'elegia i l'ègloga. ${ }^{45}$ Ara bé, allò que allunya Boscà de la majoria dels altres poetes del seu temps és la seva voluntat de trencament en aquesta

${ }^{42}$ Estic preparant l'edició critica de l'Spill de la vida religiosa per a la collecció ENC.

${ }^{43}$ Recordem l'anècdota de López de Hoyos, que creia que Petrarca havia imitat Ausiàs March, tal com explica M. de Riquer, Traducciones castellanas de Ausias March en la Edad de Oro, Barcelona, 1946, XXXI.

${ }^{44}$ Veg. M. de Riquer, Traducciones..., i HLC, II, Barcelona, 1964, 558-567, i Josephine von Hoefler, "Notes a les traduccions castellanes d'Ausiàs March en el Segle d'Or", Catalan Studies. Volume in memory of Josephine de Boer / Estudis sobre el catald. Volum en memòria de Josepbine de Boer, a cura de Joseph Gulsoy i Josep M. Solà-Solé, Barcelona, 1977, 239-249.

${ }^{45}$ Veg. A. Prieto, La poesia..., 30. 
direcció. I és que la renovació petrarquista de cap de les maneres no va implicar una total desconnexió amb el passat. D’una banda, la lírica de cançoner va persistir amb èxit - com ja he insinuat - i no va incloure mostres de la escola italiana fins a la segona meitat de segle. De l'altra, i per regla general, els poetes que adopten les novetats italianitzants les alternen amb la pràctica de la lírica de cançoner, dues pràctiques que, al cap i a la fi - i com ja he dit - provenen d'un mateix tronc comú. Això no obstant, malgrat aquesta convivència entre la tradició autòctona (octosilabo) i la tradició forana (endecasilabo), la transformació poètica del segle XVI va ser prou important com per provocar veus dissidents - recordem la Reprensión contra los poetas españoles que escriben en verso italiano de Cristóbal de Castillejo -, unes que prenen una actitud "pairalista" en identificar poesia castellana amb formes castellanes i, per tant, titllen Boscà i Garcilaso d'estrangers, $\mathrm{i}$ altres que fan crítiques d'estil. ${ }^{46}$

Però aquesta oposició és, al capdavall, anecdòtica perquè un dels grans trets de la poesia del Renaixement és precisament la barreja, i en alguns casos podríem parlar de fusió, de gèneres. Això és, justament, el que trobem en l'obra del poeta català de més entitat en aquest temps: el pintor Pere Serafi, també conegut com a "lo grech". Barceloní i, encara que probablement d'origen grec, procedent d'Itàlia - igual que un altre pintor amb afeccions poètiques: Nicolău de Credença fill, d'origen napolità,$-{ }^{47}$

${ }^{46}$ És interessant de comparar amb les que, en el pas del XVI al XVII, es faran als poetes catalans que adoptaran formes castellanes. Veg. la Sentència de Francesc Calça, dins J. Molas, "Francesc Calça...", 93-94, i el poema adreçat Als poetes catalans pel canonge Jeroni Ferrer de Guissona, dins Eduard Camps Cava i Joan Santaeulàlia Pujol, Guissona, Barcelona, 1982, 618, 620 i 622.

${ }^{47}$ Credença participà, amb una composició en castellà i una altra en català, al certamen en honor de la Immaculada (1580). Sobre els pintors estrangers establerts a Barcelona en aquesta època, veg. Joaquim Garriga, L'época del Renaixement [=História de l'art català, IV], Barcelona, 1986, 140-148. 
Serafí fou protegit dels ducs de Cardona i estigué vinculat als cercles literaris de Jeroni Galceran de Sorribes i, com Boscà, dels ducs de Somma. En la seva obra acull els diferents corrents poètics, vells i nous, que caracteritzen el XVI, tal com ho declara en la dedicatòria del seu llibre a Jeroni Galceran de Sorribes: "...havent compost en cathalá esta obra de diferents géneros y estils de metres en diverses materies..." "Vera cruilla de corrents literaris antics i moderns, de casa i de fora", dirà Riquer. ${ }^{48}$ Així, doncs, Pere Serafí recollirà, a través de tota la tradició poètica culta medieval, l'herència trobadoresca, ${ }^{49}$ si bé hi donarà sovint un tractament "renaixentista". Entre les seves composicions, de vegades relacionades amb la seva activitat pictòrica, hi trobem des d'esparses ("iOh Luc beneit, vós que la Verge pura / haveu pintat ab tant gran meravella...") fins a cançons en cobles unisonants ("D'on ve tant mal, senyora, jo suplic..."), passant pels jaumemarquians "rims de fenix" ("A vós deman, quen poesia ceptre..."), els jocs de mots ("Morir és port qu.en l'alt reviure-ns porta / dins los alts ports de les divines portes..."), la cançó de croada en forma de sonet "exortant tots los faels christians a recuperar la Terra Sancta", 50 o el tema de l'enuig ("Menjar salat, tot lo dinar sens beure...") en forma de sonet amb estrambot, etc. I, a manera de pont entre els poemes més vinculats a la tradició culta medieval catalana i els que més aviat s'arrengleren amb la nova poesia petrarquista, la influència d'Ausiàs March, l'admiració pel qual es fa especialment palesa

${ }^{48}$ HLC, III, 600. Veg. Pere Serafi, Antologia poètica, a cura d'A. Bover, Barcelona, 1987.

${ }^{49}$ És per això que Lluís Nicolau d'Olwer diu: “...per bona part de les seves poesies, ens sembla un trobador retrassat (sic)", Resum de literatura catalana, Barcelona, 1927, 22, Veg. M. de Riquer, HLC, III, 600-603.

${ }^{50} \mathrm{Veg}$. August Bover i Font, "A propòsit de la cançó de croada de Pere Serafi", dins Studia in Honorem Prof. M. de Riquer, II, Barcelona, en premsa. 
en dos sonets. El sonet XXI, on als tres grans poetes clàssics ("llatins") Homer, Virgili i Ovidi, compara els tres grans poetes moderns ("vulgars") "Petrarcha y Dant, que Italia blazona; / Ausias March qu-a Spanya tant prospera...", i el sonet "a la immortalitat de mossèn Ausiàs March, poeta català", no recollit al seu volum de poesies, però que figura a l'edició de les obres de March sorgida del cercle dels ducs de Somma i publicada a Barcelona per Claudi Bornat el 1560, al costat d'altres poemes laudatoris de Francesc Calça i d'Antic Roca. Ara bé, l'empremta de March es pot resseguir en gran nombre de les composicions de Serafi, des d'un simple eco fins a la citació textual, com per exemple l'enginyosa glossa de "Lo viscaí qui-s troba-n Alemanya" a partir d'uns versos d'aquest poema de March que el poeta sentí cantar a una dama. ${ }^{51}$ Recordem que ens trobem en plena època d'activitat de madrigalistes com Joan Brudieu i Pere Alberch Vila, que musicaren diversos poemes de March, i fins i tot alguna composició del propi Serafí, gran afeccionat a la música, ${ }^{52}$ com la famosa glossa de Bella de vós som amorós..$^{53}$ Però malgrat que - com he dit abans - per a Serafi March sigui un autor-pont, la veritat és que, com ell mateix deixa clar en un dels sonets al-ludits, el sent més a prop de Petrarca que dels trobadors:

\section{Tres són vulgars, que per semblant manera, lo principat aporten dels poetes: \\ Petrarcha y Dant, que Itàlia blazona;}

${ }^{51}$ Veg. M. de Riquer, HLC, III, 603-605.

52 Per l'inventari dels seus béns, sabem que posseïa un llaüt, una guitarra, dues bandúrries i un clavicordi; veg. J. Romeu i Figueras, "Poemes en castellà atribuïbles a Pere Serafi", BRABLB, XXXVI (1975-1976), 139.

${ }^{53}$ Veg. J. Romeu i Figueras, "Poesia catalana del segle XV. Les versions conegudes de 'Bella, de vós som amorós'", últimament recollit dins del seu llibre Poesia popular i literatura, Barcelona, 1974, 233-262. 
Auzias March, qu·a Spanya tant prospera, nos ha mostrat, per obres molt eletes, que par ab ells mereix portar corona.

I és que, probablement per la seva vinculació al grup de Ferran Folch de Cardona, dels diferents poetes catalans de l'època, Serafi - com ja indicà Joaquim Molas $~^{54}$ és el que fa una lectura més moderna de March, més propera a Boscà, per entendre'ns. I Boscà, lògicament, també és present en els poemes del pintorpoeta. D'ell extreu els irregulars estrambots amb què acaba alguns dels seus sonets, com per exemple els dedicats a una sèrie de dames barcelonines, amb els corresponents noms en acròstic, ${ }^{55}$ pràctica que, recollida del passat, la poesia del Renaixement tornà a posar en circulació. La resta dels seus sonets reflecteix l'ampliació temàtica que s'acostuma a situar a mitjan segle, és a dir, l'obertura del sonet a d'altres temàtiques ultra l'amorosa: ja he al-ludit a un enuig, a una cançó de croada i a l'elogi poètic, i hi trobem d'altres elogis, com per exemple el d'un astròleg ("Si los antichs astrolechs nostra plana..."), o la temàtica religiosa, com pot ser un sonet en acròstic dedicat a santa Magdalena (" $\mathrm{Si}$ fos gentil Maria Magdalena..."), o també la filosòfica, com en el sonet "Moral de la rahó y sensualitat" ("Dos grans camins nos mostra la natura..."), etc. Però potser on la presència de

${ }^{54}$ Veg. "Francesc Calça...", 78. Sobre la influència de March en Boscà, veg. Kathleen Mc Nerney, "Ausiàs March and Juan Boscán", Estudis de Llengua, Literatura i Cultura Catalanes. Actes del Primer Colloqui d'Estudis Catalans a NordAmèrica (Urbana, 30 de març-1 d'abril de 1978), Montserrat, 1979, 195-208.

55 Sobre els sonets amb estrambot, veg. M. de Riquer, "El cancionero barcelonés de Juan Boscán”, dins Juan Boscán y su cancionero barcelonés, Barcelona, $1945,53-54$, especialment la nota 32, explicada a les pàgs. 64-65, i A. Rossich, "La introducció...", Els Marges, 35 (en premsa). Sobre la sèrie de dames barcelonines: J. Romeu i Figueras, "Les dames cantades per Pere Serafi en els seus poemes catalans", Studia in Honorem Prof. M. de Riquer, I, Barcelona, 1986, 155-183. 
Boscà és més evident és en el Capítol moral. Els capítols i les epístoles en tercets italians, o també en vers lliure, originàriament s'empraven per a les relacions biogràfiques o familiars, bé que ben aviat experimentaren una ampliació argumental amb el contingut de les epístoles llatines dels humanistes, i no cal dir que reberen un gran estímul amb la publicació, el 1538 i en vulgar, de les Lettere de Leonardo Bruni, l'Aretí. Serafi segueix molt de prop l'epístola de Boscà a Diego Hurtado de Mendo$\mathrm{za}^{56} \mathrm{i}$ amb un to d'autèntica sinceritat desgrana uns versos autobiogràfics on mostra el seu acontentament amb un estat d'aurea mediocritas horaciana:
Io he trobat al món quant desitjava:
un ver content i vida no pensada
i un mijancer estat com demanava.
Basta'm a mi la vida concertada
sols per passar sens tembre la fortuna,
dels grans estats la vida no m'agrada.
Dels savis és sentència ja comuna
que tots extrems són mals, com és riquesa
i pobretat en son extrem cascuna.
Tenir lo mig sosté millor fermesa
puix que no falt seguint bon exercici,
sens lo perjuí dels altres ni vilesa.

Un poema on, al cap i a la fi, hi podem veure retratada una burgesia catalana que havia perdut l'empenta d'èpoques anteriors:

Y axí passam lo temps sens que-s conega,
de passió, ninguna fantasia;
prenén descanç, fugint, de enuigs, la brega.

${ }^{56} \mathrm{Ja}$ ho assenyalà M. de Riquer, "Pere Serafi", dins Comentaris crítics sobre clàssics catalans, Barcelona, 1935, 59-61. 
I al costat del sonet i de l'epístola, igual que el Boscà de l'Octava rima, Serafí conreà l'octava, com en el Càntich de amors ("Tots quants d'amor seguexen la carrera..."), una forma boccacciana que, malgrat que serví per a la creació del cànon de la poesia èpica renaixentista, comptà també amb una nombrosa pràctica lírica. D'altra banda, i a més de demandes i respostes (amb Pere Giberga, per exemple) i de sàtires, com la "tramesa per l'autor a un cavaller, la qual tracta del matrimoni", Serafí és el primer a conrear en català el madrigal ("Ay, què faré, que per servir amor...”). ${ }^{57} \mathrm{I}$, encara, un gènere tan típic ja del manierisme $\mathrm{i}$ tan adient per a un pintor-poeta com és l'emblema, si bé en aquest cas, desgraciadament, no ens n'ha arribat el vessant iconogràfic. Els emblemes aconseguiren una gran difusió a tot Europa a partir de la publicació dels Emblemata llatins d'Andrea Alciato, el 1522. Curiosament, però, els emblemes de Serafí són escrits en la mètrica del dizain francès, com els famosos emblemes de la Délie, de Maurice Scève, publicats a Lió el 1544. En aquesta mateixa ciutat, dins del segle XVI, els emblemes d'Alciato hi aconseguiren més de trenta edicions. I a Lió mateix es van fer un parell d'edicions, 1545 i 1553, dels emblemes del tolosà Guillaume de la Perrière. Aquestes colleccions, sens dubte, eren conegudes per Pere Serafí, perquè - com han demostrat Martí de Riquer i Josep Romeu i Figueras $-{ }^{58}$ els seus emblemes són pràcticament traduccions dels emblemes del Théatre des bons engins, de De la Perrière. Fet que no és gens sorprenent si tenim en compte les estretíssimes relacions que en aquesta època mantenien els llibreters barcelonins i els lionesos, els quals van pu-

${ }^{57}$ Veg. J. Rubió, HLC, II, 38; ja he parlat de la seva afecció a la música, veg., més enrera, la nota 51.

${ }^{58}$ Veg. M. de Riquer, HLC, III, 610-612, i J. Romeu, "Poemes en...", 182. 
blicar la traducció francesa de la Disputa de l'ase, d'Anselm Turmeda (1544)..$^{59}$

Però la poesia del Renaixement de cap manera no suposa un trencament amb la tradició o els gustos populars, i un bon exemple en pot ser la cort de Llorenç de Medici. És més, el Renaixement sentí un gran interès per la literatura de tipus popular, i nombrosos autors cultes miraren de dignificar-la. D'una banda, perquè els humanistes, que s'interessaven pel profit moral que hom podia extreure de la literatura clàssica, estengueren aquest interès a la literatura popular, i per tant també aquest tipus de literatura passava a ser "profitosa". En aquest procés, Erasme de Rotterdam hi va tenir un paper molt important, sobretot pel que fa a la compilació d'apotegmes, proverbis i miscellànies de tota mena, a partir de la publicació de la seva primera collecció de proverbis Adagiorum Collectanea (1500) i de la més extensa Adagiorum Chiliades (1508), ambdues molt reeditades. Un ressò català d'aquest impuls el podem trobar en Los colloquis de la insigne ciutat de Tortosa, obra que Cristòfor Despuig enllestí el $1557 .{ }^{60}$ Doncs bé, aquest interès pels proverbis és facilment relacionable amb els refranys de les cançons populars glossades pels poetes cultes, pràctica que ja venia de lluny - canalitzada a través de la dansa i la balada provençals, i generalment en versos heptasillàbics en el cas català, la glossa d'un refrany religiós havia donat origen als goigs, la d'un de profa havia originat la glossa pròpiament dita ${ }^{61}$ però que en el segle

59 Veg. J.M. Madurell i J. Rubió, Documentos para la historia de la imprenta y librería en Barcelona, Barcelona, 1955, $75^{*}-77^{\text {t4}}$.

60 Veg. el que en diu Eulàlia Duran en la seva "Introducció" a Cristòfor Despuig, Los colloquis de la insigne ciutat de Tortosa, Barcelona, 1981, 2425.

${ }^{6} \mathrm{Veg}$. A. Comas, HLC, IV, Esplugues de Llobregat, 1972; 216-219, i J. Romeu, "Poesia catalana...", 234-236, respectivament. 
XVI, dins de la inquietud humanística d'ennoblir, de "reescriure" aquesta poesia, esdevingué una autèntica moda: una mena de nobilitare renaixentista. Així, Serafí conreà el gènere gogístic (Labors del benaventurat Sanct Joan Baptista), però on excel-lí de manera extraordinària fou en la glossa profana, les seves conegudes canfons. La trentena llarga que figuren en la seva obra poètica denoten una excel-lent habilitat de Serafí per adaptar-se a aquest gènere, ${ }^{62}$ i la comparació d'aquestes glosses amb les d'altres autors permet de veure com determinats refranys populars foren glossats per més d'un poeta, de manera que constitueixen una mena de cicles: per exemple, el de Bella, de vós som amorós..., el més famós i el més afortunat, ${ }^{63}$ o el de Cridaré com un orat... $^{64}$

Ara bé, tant en els vessants més cultes de la seva poesia com en els més populars, l'obra de Serafí té un marcat deix petrarquista, ${ }^{65}$ ja sigui a través de March o a través de Boscà, tot $\mathrm{i}$ que sempre es queda a una gran distància dels seus models. I aquesta expansió del petrarquisme a tots els àmbits poètics s'explica, sobretot, per una altra interpretació del Canzionere diferent de la proposada per Bembo, és a dir, no com a biografia sinó com a "fingiment". No cal dir les possibilitats que això obrí per a molts poetes. Així, doncs, el vocabulari poètic de Serafí prové, en última instància, del Canzoniere de Petrarca i del

${ }^{62}$ Veg. M. de Riquer, HLC, III, 539-544, J. Romeu, "Elements populars i cultes en un poema de Pere Serafi", recollit darrerament per Narcís Garolera dins Anàlisis $i$ comentaris de textos literaris catalans, I, Barcelona, 1982, 166-178, i Joan Alegret, "Una cançó de Pere Serafí edició i comentari", publicat també a Anàlisis i..., III, Barcelona, 1985, 168-208.

${ }^{63}$ Veg. la nota 53.

${ }^{64}$ En preparo un estudi.

${ }^{65} \mathrm{~J}$. Romeu aporta dades que permeten de considerar Serafí com a traductor de Petrarca, "Poemes...", 181-186. 
neoplatonisme i, també, d'Ausiàs March Per això hi trobem, per exemple, el desig $i$ la desesperació, el rebuig de la dama i la frustració de l'amant, la consciència de la inutilitat dels seus esforços en front d'una dama bella i cruel mai no descrita en termes reals $\mathrm{i}$ individualitzats, etc., amb un lèxic ("vida presa", "trist, dolorós", "cadena", "cruel pena", "ple d'agonia", "maltractar-me", etc.) sotmès a unes convencions en el marc de les quals es desenvolupava el treball pròpiament creador del poeta, com era força general en la poesia amorosa europea de l'època.

Dels diferents aspectes assenyalats en la poesia de Pere Serafí, n'hi ha dos, el deute ausiasmarquià $i$ la glossa de refranys populars, que pràcticament es troben en tots els poetes catalans d'aquest període. Aquest seria el cas, per exemple, del canonge barceloní lector d'Ariosto Galceran Durall, si més no és el que es desprén dels pocs poemes seus que s'han pogut transcriure malgrat la seva mala lletra i pitjor tinta. ${ }^{66}$

Però tornant a Bembo i a la seva lectura de Petrarca, en les Prose della volgar lingua explica que "due parti sono quelle che fanno bella ogni scrittura, la gravità e la piacevolezza...”, i especifica que "sotto la piacevolezza ristringo la grazia, la soavità, la vaghezza, la dolcezza, gli scherzi, i giuochi...". ${ }^{67}$ I l'aspecte de la "piacevolezza" era precisament el que més atreia els medis cortesans. No hi ha dubte que, als Països Catalans de l'època, el millor observatori per tal d'estudiar aquest vessant poètic és la ciutat de València. Efectivament, al costat d'una poesia de certamen a la qual ja he al-ludit, ${ }^{68}$ al costat d'una poesia religiosa com la de Joan Baptista Anyes, que representa una certa reno-

${ }^{66}$ Veg. J. Rubió, HLC, II, 41-43.

${ }^{67}$ Pietro Bembo, Opere in volgare, Florència, 1961, 321-322.

${ }^{68} \mathrm{Veg}$. la nota 39. 
vació de tipus corellià, ${ }^{69} \mathrm{al}$ costat de la tradició satírica autòctona, representada ara per Andreu Martí Pineda i els seus interlocutors Jaume Siurana i Joan Valentí amb la Disputa de viudes y donzelles (1561), ${ }^{70}$ al costat de la peculiar sàtira Els mestres de València del no menys peculiar Gaspar Guerau de Montmajor, ${ }^{71}$ hi trobem la literatura generada a l'entorn de la cort de Germana de Foix i del duc de Calàbria, que malgrat que fou un centre castellanitzador produí algunes obres en llengua catalana o bilingües prou significatives. És veritat que el corrent ítalo-clàssic tenia un concepte de poesia més elevat que no pas el de simple entreteniment o habilitat cortesana, i que, per exemple, moltes obres de Petrarca figuraven a la biblioteca del duc, ${ }^{72}$ però una simple lectura de El cortesano de Lluís del Milà o de les poesies en castellà de Joan Ferrandis d'Herèdia, els escriptors més representatius d'aquesta cort, permet de veure que, al Real de València, ben sovint la "piacevolezza" derivava en un buit galanteig. El cert és que el Boscà italianista mai no hi va ser pres seriosament, ${ }^{73}$ i que les al-lusions a Petrarca en el llibre de Milà són, precisament, frivolitats cortesanes. El petrarquisme no serà acceptat a València fins més tard, a través de Garcilaso i ja en castellà. En canvi, allò que sí que hi ha en els sonets de Milà és el record d'Ausiàs March, tot i que - com diu Fuster - ja era vist més com a "filòsof" que com a "poeta". I encara que la

${ }^{69}$ Veg. E. Duran, “La vida i l'obra de Joan Baptista Anyes”, dins J.B. Anyes, $L a$ vida de sant Julia abat y martyr y de santa Basilyssa verge, d'aquell sposa, abadessa de mil santes donzelles, Barcelona, (edició facsímil), 1971, [6].

${ }^{70} \mathrm{Veg}$. Poesia erótica $i$ burlesca dels segles $X V$ i XVI, I, a cura de V. Pitarch i L. Gimeno, València, 1982, 113-151.

${ }^{71}$ Veg. Emili Casanova, “' 'Els mestres de València', de Guerau de Montmajor (1586)", Studia in Honorem Prof. M. de Riquer, II, en premsa.

72 Veg. J. Fuster, "Lectures...", 26.

${ }^{73}$ Veg. J. Fuster, "Lectures...", 17-18. 
qüestió del llemosi ${ }^{74}$ devia contribuir al fet que a València March no tingués l'atenció editorial que tingué a Barcelona, per a bé o per a mal la traducció de Romani ${ }^{75}$ hi desvetllà un interès, com ho prova el fet que un poeta com Joan Ferrandis d'Herèdia escrivís tres cobles "al modo de las de Ausias March en lengua lemosina", ${ }^{76}$ probablement relacionades amb l'activitat musical de la cort. ${ }^{77}$ Més interès, però, tenen les seves glosses de refranys populars, ${ }^{78}$ que sí que s'inscriuen en un nobilitare en el qual participaren, a més de Ferrandis, altres poetes i músics cortesans, com l'esmentat Milà, mestre de viola, tal com queda reflectit en el seu Libro de música de vibuela de mano, intitulado el Maestro (València 1536) i en l'anomenat Cançoner d'Uppsala, ${ }^{79}$ que conserva part del repertori musical de la capella del duc.

L'activitat cultural de la cort, d'alguna manera, es projectà en la societat valenciana, $\mathrm{i}$ aquest impuls l'aprofità encara el Joan Timoneda dels cançoners. ${ }^{80}$ Ja en el Sarao de amor, la convivència entre sonets, glosses, endevinalles i jocs cortesans exterioritzava una nova direcció, una direcció, diguem-ne, "cortesana" que

${ }^{74}$ Veg. J. Fuster, "Notes sobre el 'lemosi' a la València del segle Xv1", dins Universitat Autónoma de Barcelona. Doctor "bonoris causa" Joan Fuster, Bellaterra, 1984, 23-24.

75 Baltasar de Romaní, Las obras del famossissimo philosopho y poeta Mossen Osias Marco, cavallero valenciano de nacion catalan, València, 1539.

${ }^{76}$ Veg. J. Fuster, "Lectures...", 26-27.

${ }^{7}$ Com molt encertadament m'ha suggerit Joan Alegret.

${ }^{78}$ Veg. l'edició de les seves Obras, a cura de R. Ferreres, Madrid, 1955. Tinc en preparació l'edició de La vesita i de la poesia catalana de Joan Ferrandis d'Herèdia i de Joan Escrivà per a la "Biblioteca d'Autors Valencians".

79 Veg. Cincuenta y cuatro canciones españolas del siglo XVI. Cancionero de Uppsala, a cura de Rafael Mitjana, Madrid, (edició facsímil), 1980, i el treball de J. Romeu, "Mateo Flecha el Viejo, la corte literariomusical del duque de Calabria y el Cancionero llamado de Upsala", Anuario Musical, XIII (1958), 80-101.

${ }^{80}$ Veg. J. Fuster, "Introducció" a Joan Timoneda, Flor d'enamorats, València, $1973,37$. 
pretenia substituir la línia més "cancioneril". I aquesta direcció, fins $\mathrm{i}$ tot en front de l'ausiasmarquiana, és precisament la que es veu reforçada pel Flor d'enamorats. ${ }^{81}$ Ara bé, el 1569 fou nomenat arquebisbe de València Juan de Ribera, "castellà, prelat típic de l'Espanya de Felip II i de la seva ortodòxia ultrancera $\mathrm{i}$ encapsulada", com diu Fuster ${ }^{82}$ És el temps de la Contrareforma. Els escriptors valencians s'han reclòs en els salons aristocràtics i l'arquebisbe, que també va fer de virrei durant uns anys, mirarà de controlar dos importants canals d'influència: la Universitat $\mathrm{i}$ Joan Timoneda, el qual duia a terme una gran activitat editorial, i per tant de difusió d'idees. Llavors vindran els autes sacramentals... ${ }^{83}$ I proliferaran les versions contrafetes a l'espiritual. ${ }^{84}$

Per la seva part, Catalunya donarà també una veu literària contrareformista a tenir en compte: la del prevere mataroní Joan Pujol. La seva poesia religiosa o bé s'adscriurà al corrent de reescriptura dels gèneres populars (goigs i nadales, bàsicament) o bé es decantarà pel didactisme, com en el Diàlogo entre la inspiració i lo pecador, per exemple. Però, sens dubte, la característica més destacable de Pujol és la seva devoció ausiasmarquiana, evidentíssima en les glosses a poemes de March i en el panegíric de la Visió en somni, on també fa la lloança del seu amic Lluís Joan Vileta, defensor de Llull a Trento. En aquest concili, precisa-

${ }^{81}$ Veg. A. Prieto, Poesia..., 158.

82 "Introducció" a J. Timoneda, 37.

${ }^{83} \mathrm{Veg}$. Henri Mérimée, L'art dramatique à Valencia..., Tolosa de Llenguadoc, 1913, 191-227. [Trad. esp.: El arte dramático en Valencia, 1, València, 1985, 191-226]; Manuel Sanchis Guarner, "Dos 'autos' sacramentals en català escrits a instància de sant Joan de Ribera", Serra d'Or (gener 1960), 10-12; i J[oaquim] M[olas] Batllori, "Pròleg", dins Joan Timoneda, L'església militant. El castell d'Emaús, Barcelona, 1967, 5-12.

${ }^{84}$ Veg. J. Romeu, "Poesia...", 250-259. 
ment, s'establí el primer índex de llibres prohibits, entre els quals hi figurava Ausiàs March. Doncs bé, de la mateixa manera que havia rehabilitat Llull, tot "fa suposar que Vileta havia intentat una acció de 'salvament' semblant respecte a Ausiàs March, i que Pujol l'havia ajudat o, almenys, seguit en aquests esforços", com diu Karl-Heinz Anton. ${ }^{85}$ Si més no, la vinculació de Pujol a March ja no és, ni de bon tros, del mateix signe que la que hem vist en els poetes anteriors. L'anàlisi de les glosses als poemes de March permet de veure com Pujol només n'imita i n'adapta elements formals, i que - dit breument - allà on March i el Renaixement deien "saviesa", ara Pujol diu "santedat". " I aquest ús ausiasmarquià el tornem a trobar en el seu poema sobre la batalla de Lepant, única mostra de poesia èpica catalana conservada íntegra, que correspon a l'apogeu de la poesia èpica europea de les dues dècades finals del segle XVI. Cosa que - com diu Fuster - és també un italianisme. ${ }^{87}$ Es tracta d'un poema on pràcticament no hi ha reflexió teòrica sobre el gènere $\mathrm{i}$ que sovint tendeix a confondre's amb la història, si bé cal tenir present que Pujol devia topar amb la proximitat cronològica dels fets narrats a l'hora d'imaginar poèticament la història. A Castella, l'èpica traduirà l'expansió imperialista i el creixent sentiment nacionalista. En canvi els catalans, sense imperi, s'hauran de refugiar en la importància de la seva participació en la cèlebre batalla, autèntic cant de cigne de la marina catalana. ${ }^{88}$

Del poema que el mallorquí Dionís Pont dedicà al mateix

85 "Pròleg" a Joan Pujol, Obra poètica, Barcelona, 1970, 9.

${ }^{86} \mathrm{Ibidem}, 8$. Veg. també la introducció d'A. Comas a la poesia de Joan Pujol, recollida últimament a Estudis..., 45.

${ }^{87}$ Universitat de Barcelona, Solemne..., 38-39.

${ }^{88}$ Veg. L. Nicolau d'Olwer, L'expansió de Catalunya en la Mediterrània oriental, Barcelona, 1926, 232-233. 
tema, només ens n'han arribat tres estrofes. ${ }^{89} \mathrm{I}$ al costat del poema de circumstàncies Obra de menyspreu del món (1540), de Francesc d'Oleza, ran de la mort de la seva dona, i de la Devota contemplació... (1541), del seu amic Benet Espanyol, ${ }^{90}$ que precedeixen l'increment que arreu experimentà la poesia religiosa cap a final de segle, els sonets laudatoris de Jordi Dezcallar i de Pere Fiol (1590) permeten de "constatar que, si bé potser més tard que a Catalunya, els metres italians havien acabat per triomfar a Mallorca", tal com assenyala Jordi Rubió. ${ }^{91}$

Però, tot $\mathrm{i}$ que finalment la modernitat s'hi anà obrint camí, el segment literari conreat en català s'anava escurçant perillosament en front de la pressió castellana, $\mathrm{i}$ això farà que cap a final de segle en determinats sectors es produeixi un replantejament de posicions. Així, per exemple, Francesc Calça, que el 1560 feia una interpretació prou renaixentista d'Ausiàs March (situat per damunt d'Homer), ${ }^{92}$ experimentarà un replegament que s'explicita en la seva sentència al certamen celebrat amb motiu de la canonització de sant Ramon de Penyafort (1601), on confon nacionalisme amb tradició. ${ }^{93}$ Es tracta d'una actitud semblant a la que unes dècades abans s'havia donat a Castella, on els sectors conservadors van identificar poesia castellana amb formes caste-

${ }^{89}$ Veg. Joaquim Maria Bover, Biblioteca de escritores baleares, II, Palma de Mallorca, 1868, 131.

${ }^{90}$ Veg. F. d'Olesa, Obra del menyspreu del món, a cura d'Antoni Pons, Ciutat de Mallorca, 1931. El poema de B. Espnyol és reproduït per J.M. Bover, Biblioteca.... I, Palma de Mallorca, 1868, 254-257 $\mathrm{i}$ inclòs per Albert Hauf en l'apèndix de la seva edició de Joan Eixemeno, Contemplació de la Santa Quarentena, Montserrat, 1986, 125-129.

${ }^{91}$ HLC, II, 45. Els sonets laudatoris esmentats encapçalen el llibre de Francesc Terrades, Compendi de la pesta, Palma de Mallorca, 1590, i són reproduïts per J.M. Bover, Biblioteca..., I, 238 i 298, respectivament.

92 Veg. J. Molas, "Francesc Calça...”, 87.

${ }^{33}$ Veg. J. Molas, "Francesc Calça...", 93-94. 
llanes i, per tant - com hem vist abans -, titllaven Boscà i Garcilaso d'estrangers. És clar que als Països Catalans hi havia en joc un altre element, i precisament de primer ordre: la llengua. I això podria explicar la radicalització de Calça, la posició del qual, més endavant, serà continuada pel canonge Jeroni Ferrer de Guissona ${ }^{94}$ bé que amb matisos significatius. Però això ja ens portaria a un altre tema. ${ }^{95}$

\section{AUGUST BOVER I FONT}

UNIVERSTTAT DE BARCELONA

${ }^{94} \mathrm{Veg}$. el seu poema Als poetes catalans, relacionat a la nota 46 .

${ }^{95}$ Sigles utilitzades en aquest article:

BRABLB: Boletín de la Real Academia de Buenas Letras de Barcelona. ENC: "Els Nostres Clàssics".

HGLH: Historia General de las Literaturas Hispánicas. HLC: Història de la Literatura Catalana.

RABLB: Real Academia de Buenas Letras de Barcelona. 